University of Nebraska - Lincoln

DigitalCommons@University of Nebraska - Lincoln

USDA National Wildlife Research Center - Staff

Publications
U.S. Department of Agriculture: Animal and Plant Health Inspection Service

October 2007

\title{
Comparison of immune and adverse effects induced by AdjuVac and Freund's complete adjuvant in New Zealand white rabbits (Oryctolagus cuniculus)
}

Jenny G. Powers

National Wildlife Research Center, Animal and Plant Health Inspection Service, United States Department of Agriculture

Paul B. Nash

National Wildlife Research Center, Animal and Plant Health Inspection Service, United States Department of Agriculture

Jack C. Rhyan

National Wildlife Research Center, Animal and Plant Health Inspection Service, United States Department of Agriculture

Christi A. Yoder

National Wildlife Research Center, Animal and Plant Health Inspection Service, United States Department of Agriculture

Lowell A. Miller

National Wildlife Research Center, Animal and Plant Health Inspection Service, United States Department Folllogricthis and additional works at: https://digitalcommons.unl.edu/icwdm_usdanwrc

Part of the Environmental Sciences Commons

Powers, Jenny G.; Nash, Paul B.; Rhyan, Jack C.; Yoder, Christi A.; and Miller, Lowell A., "Comparison of immune and adverse effects induced by AdjuVac and Freund's complete adjuvant in New Zealand white rabbits (Oryctolagus cuniculus)" (2007). USDA National Wildlife Research Center - Staff Publications. 713. https://digitalcommons.unl.edu/icwdm_usdanwrc/713

This Article is brought to you for free and open access by the U.S. Department of Agriculture: Animal and Plant Health Inspection Service at DigitalCommons@University of Nebraska - Lincoln. It has been accepted for inclusion in USDA National Wildlife Research Center - Staff Publications by an authorized administrator of DigitalCommons@University of Nebraska - Lincoln. 


\title{
Comparison of immune and adverse effects induced by AdjuVac and Freund's complete adjuvant in New Zealand white rabbits (Oryctolagus cuniculus)
}

\author{
Jenny G. Powers, DVM ${ }^{1,2}$, Paul B. Nash, PhD ${ }^{1}$, Jack C. Rhyan, DVM, $M S^{1}$, Christi A. Yoder, PhD $D^{1}$ or \\ Lowell A. Miller, $P h D^{1}$
}

Though Freund's complete adjuvant effectively increases immune response to vaccines in various species, its potentially severe inflammatory effects have led many animal researchers to seek alternative immunological adjuvants. In a study of New Zealand white rabbits, the authors compared the immune and adverse effects of Freund's complete adjuvant with the effects of two formulations of AdjuVac, an immunological adjuvant previously developed by their group. All three adjuvants improved humoral immune response but also caused inflammation. Inflammatory reactions caused by AdjuVac, however, tended to be less severe than those caused by Freund's complete adjuvant.

Of the immunological adjuvants available today, Freund's complete adjuvant (FCA) is one of the most effective, yet controversial. FCA contains mineral oil ( $~ 85 \%)$, a mannide monooleate emulsifier (often Aracel A) ( 15\%) and killed mycobacteria (typically Mycobacterium tuberculosis or M. butyricum; $0.1 \%$ ). This adjuvant is commonly added to weak immunogens to increase immune response in vaccinated animals. The initial vaccination is routinely followed several weeks later by a booster vaccination formulated with Freund's incomplete adjuvant (FIA), which is similar to FCA but does not include mycobacteria. This vaccination strategy effectively stimulates both cell-mediated and humoral immune responses to a wide variety of antigens ${ }^{1,2}$. It has been used for decades in laboratory and research settings to stimulate hyperimmune serum production as well as protective immunity in a broad range of species.

Along with its benefits, FCA also has distinct disadvantages. Depending on the target species, vaccine dose and route of administration, FCA can cause severe local and systemic acute and chronic inflammation ${ }^{3-7}$. The inflammatory lesions associated with FCA have been attributed to formation of an antigen/adjuvant depot, which promotes antigen transport to immune effector cells and interactions with antigen-presenting cells ${ }^{8}$. This inflammatory response generates both beneficial and detrimental effects. Inflammatory mediators, such as leukocytes and cytokines, incite $\mathrm{B}$ and $\mathrm{T}$ lymphocyte activation and differentiation. This triggers specific antibody production and activates effector $\mathrm{T}$ cells and antigen-presenting cells ${ }^{9}$. These same processes can also induce swelling, erythema and pain, both locally and systemically. FCA's adverse side effects render it inappropriate for use in humans or in clinical veterinary settings. Concerns about animal welfare have driven researchers to look for alternative adjuvants ${ }^{5}$.

Numerous studies have compared Freund's adjuvant combination with alternative adjuvant formulations ${ }^{10-18}$. The results reflect much discrepancy in efficacy and secondary side effects ${ }^{19}$. Therefore, the need remains for a versatile and effective adjuvant alternative to $F C A$ that capitalizes on its benefits while minimizing its negative effects.

AdjuVac, an experimental adjuvant developed and previously described ${ }^{20-23}$ by members of our group, contains small amounts of Mycobacterium avium

'National Wildlife Research Center, Animal and PJant Health Inspection Service, United States Department of Agriculture, 4101 LaPorte Avenue, Fort Collins, CO 80521. 'Present Address: National Park Service, 1201 Oakridge Dr., Suite 200, Fort Collins, CO 80525. Correspondence should be addressed to J.G.P. (jenny__powers@nps.gov). 
subspecies avium $(\leq 200 \mathrm{~g} / \mathrm{ml})$ emulsified in either mineral oil or squalene, a biodegradable oil. AdjuVac contains microgram quantities of mycobacteria rather than the milligram amounts found in FCA and contains an alternate species of mycobacterium that may have different immune stimulatory effects. In addition, certain formulations of AdjuVac contain a biodegradable oil, which may alter depot characteristics. AdjuVac has been investigated in domestic cats (Felis catus) ${ }^{20}$, horses (Equus caballus) ${ }^{21}$, feral swine (Sus scrofa) ${ }^{22}$ and bison (Bison bison) ${ }^{23}$, as well as other domestic and laboratory animals (L.A. Miller, unpublished observations). AdjuVac is primarily intended for use in combination with immunocontraceptive vaccines in domestic and wild animals. The purpose of this study was to compare physiological, histological and pathological changes in New Zealand white rabbits (Oryctolagus cuniculus) vaccinated intramuscularly (i.m.) with FCA or with one of two formulations of AdjuVac. We investigated biological effects that can be attributed primarily to the immune system. The antigen we used was a small, nonimmunogenic self-peptide, gonadotropin releasing hormone ( $\mathrm{GnRH}$ ), coupled to a large, highly immunogenic carrier protein, keyhole limpet hemocyanin (KLH).

\section{METHODS}

\section{Rabbits}

We used female New Zealand white rabbits weighing $2.1-2.7 \mathrm{~kg}$ each. We caged each rabbit separately at a temperature of $16-20^{\circ} \mathrm{C}$ with 12 -h light:12-h dark cycles. We fed rabbits Purina lab diet \#5326, a commercial, alfalfa-based, high-fiber pelleted food. Water was available ad libitum.

We divided the 26 rabbits into six treatment groups $(n=4)$ and one control group $(n=2)$. Two treatment groups were given each of the three types of adjuvant used in this study: FCA, AdjuVac formulated with nonbiodegradable mineral oil (AVM), and AdjuVac formulated with the biodegradable oil squalene (AVS). One of the two groups receiving each adjuvant was given an initial vaccination only ( $100 \mu \mathrm{g}$ of $\mathrm{GnRH} / \mathrm{KLH}$ ), and the other group was given an initial vaccination of 50 $\mu \mathrm{g}$ of $\mathrm{GnRH} / \mathrm{KLH}$ plus a booster vaccination of $50 \mu \mathrm{g}$ of GnRH/KLH 4 weeks later. All initial vaccinations in treatment groups included mycobacteria-containing adjuvants. Booster vaccinations were formulated with AdjuVac incomplete (without mycobacteria; 2 of $4 \mathrm{rab}$ bits), AdjuVac complete (with mycobacteria; 2 of $4 \mathrm{rab}$ bits) or FIA ( 4 of 4 rabbits). We vaccinated the control group with $\mathrm{GnRH} / \mathrm{KLH}$ in saline without adjuvant. One rabbit in the group that was to receive FCA initial vaccination only died before the beginning of the study, leaving that group with only three rabbits.

To approximate vaccination procedures likely to be used in a clinical or field setting in various species, we injected rabbits $\mathrm{i} . \mathrm{m}$. with $0.5 \mathrm{ml}$ in the semimembranosus/semitendinosus musculature. We shaved the injection sites using a \#40 blade one week before injection. The initial injections were made in the left hind leg, and booster vaccinations were made in the right hind leg.

\section{Vaccine preparation}

The GnRH/KLH/AdjuVac vaccine formulation used in these experiments has been previously published ${ }^{20}$. The 10-amino acid GnRH peptide was synthesized at Macromolecular Resources, Colorado State University (Fort Collins, CO). We increased the antigenicity of the hapten by combining multiple copies of the peptide with the large immunostimulatory carrier molecule $\mathrm{KLH}$ (Pierce Endogen, Roclfford, IL) via maleimide activated coupling ${ }^{24}$. We combined the aqueous GnRH/KLH conjugate in a $1 / 1$ ratio $(v / v)$ with the oil-based adjuvants to create water-in-oil emulsions. We prepared the emulsion by repeatedly passing the material through a 22-gauge needle into an empty syringe until it was stiff. We evaluated emulsions by checking their dispersion across a water surface.

We prepared AdjuVac adjuvants by modifying the commercially available veterinary vaccine Mycopar (Fort Dodge Animal Health, Fort Dodge, IA). Using either non-biodegradable mineral oil or the biodegradable oil squalene, we diluted small volumes of Mycopar until the bacterial fraction was approximately equivalent to $200 \mu \mathrm{g} / \mathrm{ml}$ or less. We prepared a similar water-in-oil emulsion vaccine using FCA ( $85 \%$ Drakeol $5 \mathrm{NF}, 15 \%$ Aracel A, $0.1 \%$ M. butyricum dry cells; Calbiochem-Novabiochem Corporation, San Diego, CA) or FIA combined with the GnRH/KLH aqueous solution.

\section{Clinical and pathological measurements}

We measured each rabbit's body weight at the start of the study and before euthanasia. We observed rabbits on a daily basis for clinical signs of pain or systemic illness including lack of appetite, lameness, withdrawal or vocalization when the injection site was palpated, and swelling or erythena at the injection site. With minimal animal handling, we recorded rectal temperature before treatment and at the start of each sampling session. We drew pretreatment blood from a peripheral ear vein for evaluation of creatine phosphokinase (CPK) concentrations and for complete blood counts (CBCs). We drew additional venous blood samples for CPK evaluation $24 \mathrm{~h}$ and $72 \mathrm{~h}$ after administration of the primary injection. We determined serum CPK concentrations using CPK procedure \#520 from Sigma Diagnostics (SigmaAldrich, St. Louis, MO).

We submitted whole blood collected before treatment and $72 \mathrm{~h}$ after initial injection to Colorado State University's Veterinary Diagnostic Laboratory for CBC analysis. $\mathrm{CBC}$ parameters included: total nucleated cell 
count, differential, red blood cell count, platelets (all cell counts were expressed as cells $/ \mu \mathrm{l}$ ), plasma protein ( $\mathrm{g} / \mathrm{dl})$, hemoglobin concentration ( $\mathrm{g} / \mathrm{dl}$ ), pack cell volume (\%), mean corpuscular volume (fl), mean corpuscular hemoglobin concentration $(\mathrm{g} / \mathrm{dl})$ and fibrinogen concentration (mg/dl).

Because we collected samples for CPK evaluation and for CBCs before administering booster vaccinations, we did not distinguish between single-injection and dualinjection groups when analyzing these data.

We anesthetized each rabbit 12 weeks after initial vaccination and collected blood via intracardiac puncture. We then euthanized rabbits with pentobarbital (390 $\mathrm{mg} / \mathrm{ml}$ ) and phenytoin sodium (50 $\mathrm{mg} / \mathrm{ml}$ ) (Euthasol, Delmarva Laboratories, Inc., Midlothian, VA). We carried out a complete necropsy on each rabbit. We grossly examined injection site lesions, measured their volume by taking three-dimensional measurements and calculating cubic volume for the approximate shape, and then incised and described them. We placed sections of injection site lesions, lung, heart, liver, kidney, spleen, duodenum, ovary, uterus, and popliteal and internal iliac lymph nodes in $10 \%$ neutral buffered formalin and processed the samples for histopathological evaluation. Injection site lesions were blindly scored on a semi-quantitative scale, using methods similar to those previously described ${ }^{17}$. We evaluated the following characteristics: vacuoles, macrophages, giant cells, mature neutrophils, lymphocytes/plasma cells and relative necrosis or mineralization. We rated the degree of each characteristic as marked (3), moderate (2), mild (1) or absent (0).

\section{Antibody assay}

We collected blood 2, 4, 8 and 12 weelcs after initial immunization and 2, 4 and 8 weeks after booster immunization in dual-injection groups for measurement of GnRH antibody titers. We determined antibody titers using a noncompetitive indirect enzyme-linked immunosorbent assay. We conjugated bovine serum albumin-with GnRH and used it to coat Immulon $2 \mathrm{HB}, 96$-well microtiter plates (Thermo Electron Corporation, Waltham, MA) using a bicarbonate buffer. After incubation, we rinsed plates and blocked them with 1:20 Sea Block (Pierce Biotechnology, Inc., Rockford, IL) phosphate-buffered saline (PBS) solution. We washed plates with PBS after incubating them overnight at $4{ }^{\circ} \mathrm{C}$. We added $100 \mu \mathrm{l}$ of a 1:4,000 dilution of test sera to the first well of each row. We serially diluted the sera 1:2 with PBS up to $1: 512,000$. After $2 \mathrm{~h}$ of incubation at room temperature, we washed the plates and added $100 \mu \mathrm{l}$ of a 1:3,000 goat antibody to rabbit Immunoglobulin G, conjugated to horseradish peroxidase (Sigma-Aldrich). Color was developed by $3,3^{\prime}, 5,5^{\prime}$ tetramethylbenzidine (Sigma-Aldrich). We measured the optical densities of individual wells via absorbance using a Dynatech
MR 5000 microplate reader at a wavelength of $410 \mathrm{~nm}$ (Dynatech Laboratories, Alexandria, VA). Antibody titers were determined when optical density values dropped more than $50 \%$ between serial dilutions.

\section{Statistical evaluation}

We analyzed lesion data using analysis of variance (PROC GLM). We analyzed all other data as a mixedeffects model (PROC MIXED) using SAS version 9.1 (SAS Institute, 2003), defining significance as $P \leq 0.05$. We investigated the effects of treatment, time and the interaction of the two factors.

\section{RESULTS}

\section{Clinical observations}

We intensively monitored rabbits throughout the study, and none demonstrated clinical signs of pain or lameness. On several occasions rabbits from various treatment groups exhibited small hard nodular swellings at the injection sites. These swellings did not show external evidence of abscessation or draining. There were no significant differences between treatment groups in rabbits' overall mean live weights $(P=0.6925)$ or weight gains $(P=0.6438)$. Mean weights $( \pm S D)$ for all rabbits at the start and end of the study were $3.18 \pm 0.18 \mathrm{~kg}$ and $3.83 \pm 0.23 \mathrm{~kg}$, respectiveiy. There were no significant differences between treatment groups in mean rectal body temperature at any of the sampling points ( $P=0.9775$; data not shown). In 8 of 189 measurements, rabbits had clinically elevated rectal temperatures of $39.5^{\circ} \mathrm{C}$ or above (5 in rabbits treated with AVS, 1 with AVM and 2 with FCA).

\section{Creatine phosphokinase}

Serum CPK concentrations did not differ among groups $(P=0.3657)$ at any time point but did differ within each group over time $(P=0.0088)$. In all treatment and control groups, serum CPK concentrations increased during the first $24 \mathrm{~h}$ after initial injection and then decreased between $24 \mathrm{~h}$ and $72 \mathrm{~h}$ (Fig. 1). In rabbits treated with AVS and AVM, the increase in mean serum CPK concentration during the first $24 \mathrm{~h}$ was moderate, with a drop back to baseline between $24 \mathrm{~h}$ and $72 \mathrm{~h}$. CPK concentration in control rabbits increased similarly during the first $24 \mathrm{~h}$. By $72 \mathrm{~h}$ after injection, however, the control rabbits had lower CPK concentrations than rabbits in any of the treatment groups. In rabbits treated with FCA, the increase and subsequent decrease in CPK concentration was almost twice as large. Before treatment, mean CPK concentrations were significantly higher in rabbits treated with FCA than in rabbits in the other treatment and control groups $(P=0.0385)$; this difference was probably attributable to abnormally high CPK concentrations in two of the rabbits 


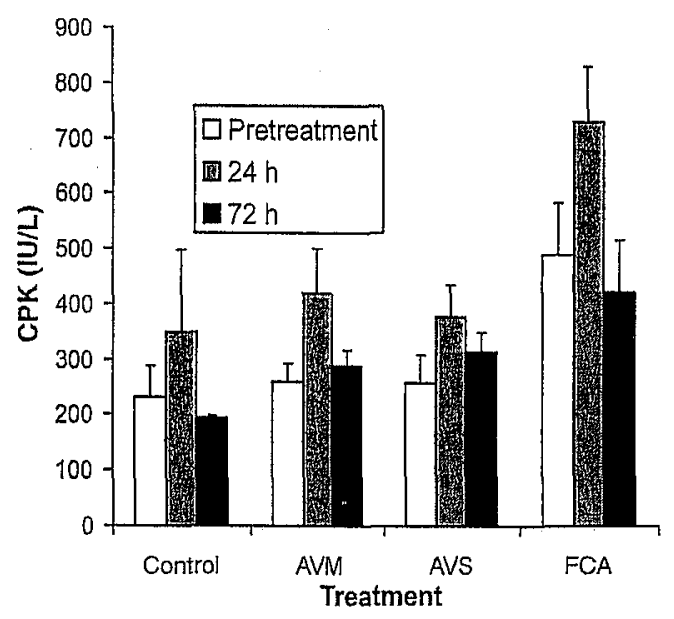

FIGURE 1 | Serum CPK concentrations (IU/L) before treatment and $24 \mathrm{~h}$ and $72 \mathrm{~h}$ after treatment with different adjuvants. Bars indicate standard error.

in the FCA group. Mean CPK concentrations before treatment for the AVM, AVS and control groups were clinically normal $(<400 \mathrm{IU} / \mathrm{L})^{25}$.

\section{Complete blood counts}

We observed few changes over time in $\mathrm{CBC}$ parameters. Fibrinogen concentration was the only parameter that changed consistently between pretreatment and $72 \mathrm{~h}$ after treatment. Differences in mean fibrinogen concentrations between treatment groups only approached significance $(P=0.0977 ;$ Fig. 2). Within each treatment group, there was a significant increase in the mean fibrinogen concentrations between pretreatment and $72 \mathrm{~h}$ after injection $(P=0.0022)$. Before treatment, fibrinogen concentrations in all rabbits were within the normal reference range $(200-400 \mathrm{mg} / \mathrm{dl})^{26}$. Rabbits treated with FCA had a larger increase in fibrinogen than did rabbits treated with AVM $(P=0.0104)$ but not those treated with AVS $(P=0.5433)$. In four rabbits, fibrinogen concentrations exceeded the reference range at this time point $(500-700 \mathrm{mg} / \mathrm{dl})$. Two of these four rabbits were treated with AVS, and the other two were treated with FCA.

\section{Antibody production}

We distinguished between initial injections and booster injections when evaluating antibody titers. Before vaccination, no rabbits had measurable GnRH antibody titers. After treatment, regardless of adjuvant type, all rabbits treated with adjuvants developed high antibody titers $(P$ $=0.9612$ ). Neither of the control rabbits developed $\mathrm{GnRH}$ antibody titers. Within 4 weeks of initial vaccination, 21 of the 23 rabbits treated with adjuvants developed GnRH antibody titers that were detectable at a serum dilution of 1:512,000. Nearly all rabbits maintained this titer until necropsy, which was carried out 12 weeks after the initial vaccination. Although the differences were not statisti- cally significant, absorbance at a dilution of 1:512,000 was initially higher in AVM-treated rabbits ( 4 weeks after vaccination); however, rabbits treated with single-injection FCA had higher absorbance 12 weeks after vaccination (Fig.3). A booster injection at 4 weeks, intended to augment antibody responses, did not increase absorbance at a dilution of 1:512,000 above values observed in singleinjection groups.

\section{Lesions}

We distinguished between initial injections and booster injections when examining lesion data. Primary lesions (left hind leg) differed in size among groups $(P=0.0282)$, whereas differences between secondary lesions (right hind leg) only approached statistical significance $(P=0.0683)$. At necropsy, all adjuvant-treated rabbits had lesions at the initial injection site in the left rear leg semimembranosus/semiten dinosus musculature. Neither control rabbit had any grossly visible injection site abnormalities. Affected areas of muscle were typically firm and white or yellow in appearance. Often there were discrete nodules within the affected areas. Lesions tended to be locally extensive, often dissecting along tissue planes and bound by muscle fascia. Two rabbits, one treated with AVM and one with FCA, had hard nodules in musculature distant from the injection site. In addition, these two rabbits both had popliteal lymph nodes that were larger than the contralateral lymph nodes. On average, rabbits treated with FCA had the largest lesions (mean \pm s.d. $\left.=18.1 \pm 10.9 \mathrm{~cm}^{3}\right)$. In rabbits treated with both primary and booster vaccinations, the second injection site lesion tended to be smaller than the primary lesion (Table 1). Lesions associated with booster vaccinations in the AVS treatment group were smaller than those in the AVM treatment group, but not those in the FCA treatment group.

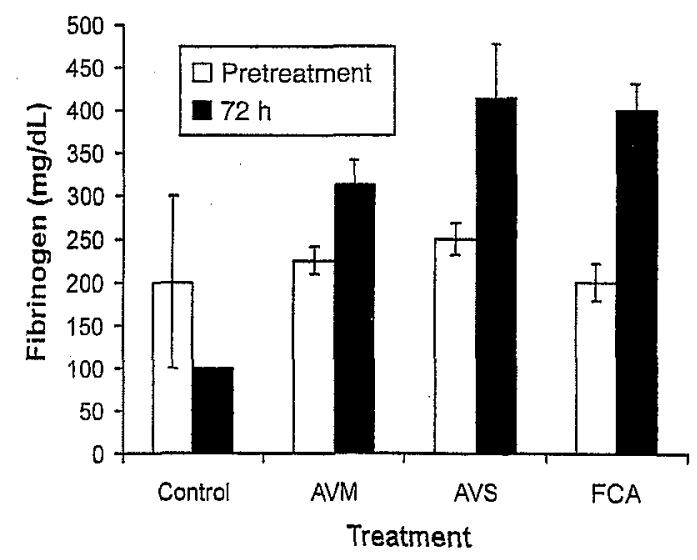

FIGURE 2 | Serum fibrinogen concentrations ( $\mathrm{mg} / \mathrm{dl}$ ) before treatment and $72 \mathrm{~h}$ after treatment with different adjuvants. Bars indicate standard error. 


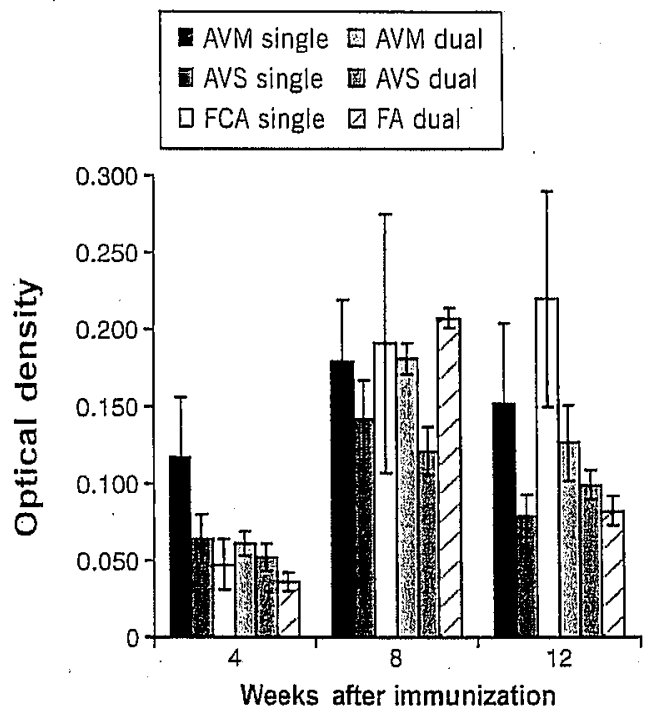

FIGURE 3 | Optical density ( $410 \mathrm{~nm}$ ) of GnRH antibodies over time for the six treatment protocols tested, in 1:512,000 serum dilution after detection with enzyme-linked immunosorbent assay. Bars indicate standard error. The number of vaccinations each group received is indicated (single or dual). FA, Freund's adjuvant combination.

At necropsy, all injection site lesions were granulomatous (Fig. 4). Lesions tended to be partially circumscribed with focal inflammatory cell infiltrates extending between surrounding muscle bundles and myofibers. Often, focal degeneration was identified in surrounding myofibers. Cellular infiltrates consisted of large sheets of mixed inflammatory cells including epithelioid macrophages, mature neutrophils, lymphocytes, plasma cells and giant cells surrounding small to large vacuoles. The vacuoles were considered to be oil droplets. In several lesions, vacuoles were surrounded by heterophils and multinucleated giant cells. The vacuoles were occasionally accompanied by coagulative necrosis and focal mineralization.

There were no differences between treatment groups in the relative number of vacuoles $(P=0.2164)$, mac- rophages (no $P$ value because all rabbits had the same score), giant cells $(P=0.0980)$, neutrophils $(P=0.1979)$ or lymphocytes $(P=0.2455)$. Necrosis and mineralization scores did not differ between treatment groups $(P=0.4922$ and $P=0.6256$, respectively; Table 2).

\section{Additional histopathological observations}

In all treated rabbits, reproductive tracts, including uterus and ovaries, were small and immature on gross examination. Reproductive tracts in control rabbits were clinically normal. Examination of a midline cut surface of one or both ovaries rarely revealed follicles. Those follicles that were present appeared smaller than those seen in control rabbits. Three treated rabbits had enlarged popliteal lymph nodes. There was no correlation between lymph node enlargement and treatment group ( $P=0.2663)$. We did not observe gross abnormalities in lung, heart, liver, kidney, spleen or duodenum tissues in any experimental rabbits.

\section{DISCUSSION}

This study compared the biological effects of FCA, AVM and AVS when combined with a common antigen and injected into domestic laboratory rabbits. Our results showed that primary deep i.m. injections with water-in-oil emulsions containing killed mycobacteria are effective in inducing high levels' of antibody production but cause granuloma formation and acute and chronic inflammation. This finding is consistent with those of numerous studies investigating the use of Freund's adjuvants ${ }^{1-3,5,10,13,14}$. This study is unique in that it evaluated potentially subtle differences in the severity of the immune-mediated effects generated by the three adjuvants tested.

None of the treatment groups in this study exhibited the more severe systemic and local inflammatory reactions reported to be associated with FCA, such as lack of appetite, lameness, ulceration, necrotizing dermatitis, muscle atrophy, fistulous tracts, hypersensitivity pnuemonitis and embolic pneumonia ${ }^{4,19}$. There were,

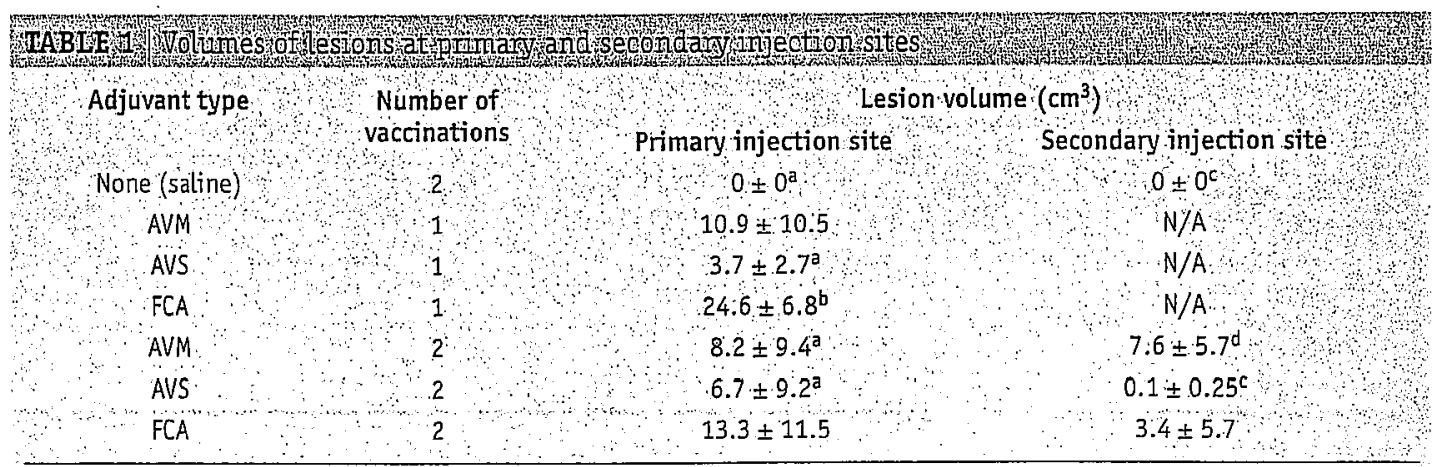

Values shown are mean \pm s.d. Power to detect a difference between treatments was $37-49 \%$. Means within columns with different superscripts are significantly different from one another $(P<0.05)$. Values without superseripts are not significantly different from any other values in the column. N/A, not applicable ( $\mathrm{no}$ secondary vaccination administered). 


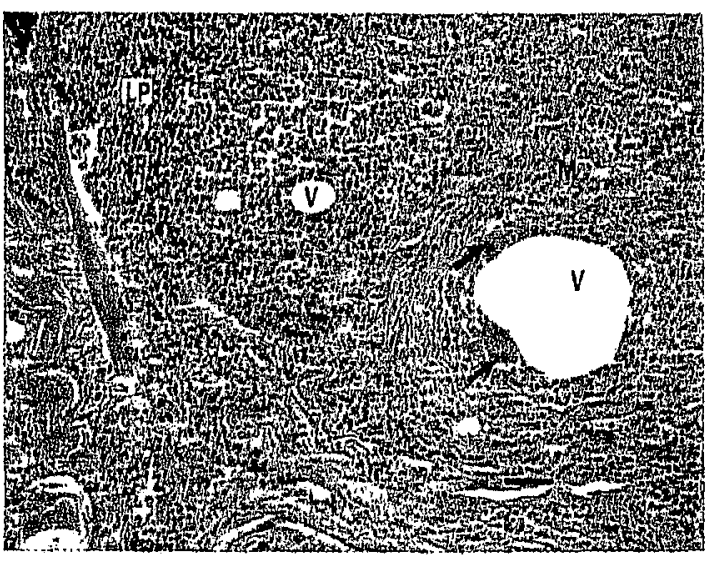

FIGURE 4 | Photomicrograph of injection site lesion produced by vaccination with FCA. The lesion is characteristic of those produced by all treatments and contains small to large vacuoles (V) surrounded by macrophages (M), multinucleated giant cells (arrows) and focal accumulations of lymphocytes and plasma cells (LP). Bar represents $60 \mu \mathrm{m}$.

however, many indications of inflammation in all treatment groups. All rabbits, including the control group (vaccinated with saline/antigen), had increased serum CPK concentrations after vaccination. CPK is primarily a cytosolic enzyme of myocytes, released when the cell membrane is damaged and the cell undergoes myonecrosis. CPK has a short plasma half-life, and serum levels usually return to normal 2-3d after the cessation of the insult or injury ${ }^{27}$. CPK is therefore a good indicator of acute muscle damage. In this case, the myonecrosis may have resulted from tissue trauma from the needle combined with the physical presence of the vaccine in the muscle, in addition to the vaccine's molecular function. FCA and other adjuvants have been shown to increase CPK concentration in similar studies ${ }^{13,28}$. In this study, although the difference was not statistically significant, treatment with FCA was associated with the highest mean CPK concentration $24 \mathrm{~h}$ after treatment. Given the variation observed, our power to detect a difference between groups was $21.8 \%(a=0.05)$. Therefore, we may not have detected a difference between groups because of inadequate sample size, rather than a true lack of divergence between the treatment groups.

Two rabbits whose $\mathrm{CPK}$ values were outliers and were elevated at all time points increased the mean CPK concentration in the FCA treatment group; however, the relative change in their CPK concentrations over time was similar to that of other FCA-treated rabbits. Although their veterinary records did not indicate that the rabbits had experienced increased handling stress, stress could have contributed the elevation in their initial serum CPK concentrations. CPK concentrations of most rabbits exceeded the normal range (>350-400 IU/L) $24 \mathrm{~h}$ after vaccination, although none of the values were clinically extreme. We conclude that myonecrosis occurred in association with inmunization, that it may have been more severe in FCA-treated rabbits and that it was diminished within $72 \mathrm{~h}$ after immunization.

Iike $\mathrm{CPK}$, plasma concentrations of fibrinogen can act as a measure of inflammation. Fibrinogen is an acute phase-reactant protein produced by the liver, which serves as a substrate for thrombin in the formation of fibrin during homeostasis. Increased fibrinogen concentration is a good indicator of active inflammation and is useful in assessing an inflammatory response ${ }^{29}$. In FCA-treated rabbits, fibrinogen concentrations were consistently higher $72 \mathrm{~h}$ after vaccination than before treatment (average increase was $200 \mathrm{mg} / \mathrm{dl}$ ). In two of seven FCA-treated rabbits, the increased fibrinogen concentrations exceeded the normal range in rabbits $(200-400 \mathrm{mg} / \mathrm{dl})^{26}$. Though mean fibrinogen concentrations also increased over time in rabbits treated with AVM and AVS, the increase was neither as consistent nor as high as that observed in the FCA treatment groups. Our power to detect differences in fibrinogen concentrations between groups was $14.9 \%$. Small sample size and relatively large variation in both fibrinogen and $\mathrm{CPK}$ concentrations limited our ability to detect statistically significant increases in these indicators of inflammation. However, both trends suggest that FCA-treated rabbits had greater acute inflammation.

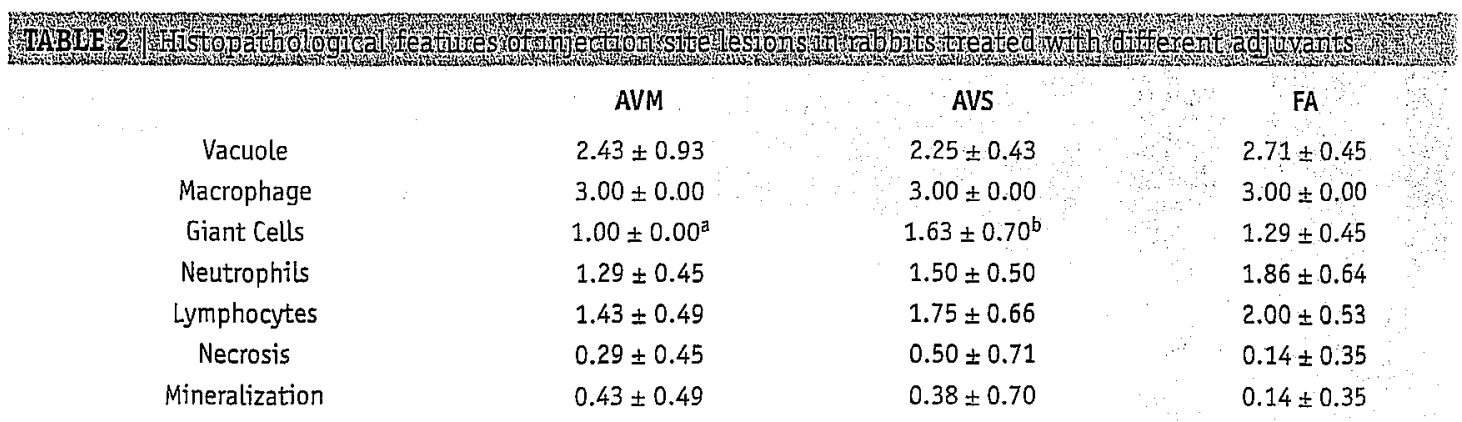

Values shown are the mean \pm s.d. of the degree to which each histological feature was present, using the following scale: 3 , marked; 2 , moderate; 1 , mild; 0 , absent. Means within rows with different superseripts are significantly different from one another $(P<0.05)$. Values without superscripts are not significantly different from any other values in the row. 
Gross and histopathological examination of primary injection site lesions showed moderate to severe focal chronic granulomatous inflammation in all rabbits treated with adjuvants. Granulomatous inflammation is classically characterized by well-circumscribed areas of large numbers of modified tissue macrophages (epithelioid cells or multinucleate giant cells), polymorphonuclear leukocytes and lymphocytes. Granulomas generally form in response to a chronic inflammatory stimulus such as an indigestible foreign protein or a type IV hypersensitivity reaction and may remain in tissue for the duration of the stimulus. In this study, though the differences were not statistically significant, lesion size tended to be larger in volume with higher numbers of oil-droplet vacuoles, mature neutrophils and lymphocytes in FCAtreated rabbits than in rabbits treated with AVM or AVS: All groups had equally extensive lesion infiltration with macrophages. Lesions associated with booster vaccinations (right leg) were smaller in rabbits treated with AVS than in those treated with AVM. Though this is probably an artifact of small sample size (power is 37-49\%), it may indicate that biodegradable oil incites less chronic inflammation during the secondary or anamnestic response than non-biodegradable mineral oil. Additional experiments would be necessary to investigate this hypothesis.

Antibody production in all adjuvant-treated rabbits was high. Over the course of the 12-week study, we observed no difference in the effects of the various adjuvant types and immunization protocols on antibody production or persistence. Nearly all treated rabbits had detectable $\mathrm{GnRH}$ antibody titers at a dilution of 1:512,000 by 4 weeks after the initial vaccination. In previous experiments with similar immunization protocols in other species, antibody titers at dilutions greater than $1: 400,000$ (domestic cats) ${ }^{20}$ and $1: 100,000$ (bison) $)^{23}$ were shown. Limitations of the enzyme-linked immunosorbent assay did not allow us to quantitatively measure antibody production beyond this dilution; we were therefore unable to identify end-point titer differences between treatment groups. Analysis of the optical density at this dilution did not show any differences between treatment groups. This may be due to our low power to detect differences $(38.7 \%)$ rather than a true lack of treatment effect. Though the difference was not statistically significant, rabbits treated with FCA continued to show increased absorbance at the 1:512,000 dilution 12 weeks after treatment, whereas absorbance levels in all other treatment groups dropped between 8 and 12 weeks. Therefore, it is possible that FCA incites a more potent humoral inmune reaction than AVM or AVS. Larger sample sizes, a more complete assay and longer. experimental duration would be necessary to determine whether different treatments have different effects on antibody production and persistence. Our study does show that AVM, AVS and FCA effectively stimulate humoral inmune responses in rabbits with a single immunization or in conjunction with a booster vaccination.
Elevated GnRH antibody titers correlated well with relative immaturity of the reproductive tract. On gross examination, all rabbits vaccinated with a water-in-oilbased adjuvant had small, underdeveloped ovaries with few or no visible follicles. Control rabbits vaccinated with GnRH-KLH in saline had larger ovaries and uteri and follicles of various sizes. Microscopically, ovaries from treated rabbits contained primordial follicles and small numbers of preantral follicles but no antral or preovulatory follicles. Whereas ovaries from control rabbits showed normal postpubertal follicular development, ovaries from treated rabbits were characteristic of prepubertal development.

No single physiological parameter provides a complete picture of the safety and efficacy of a vaccine formulation. Considered together, however, the inflammatory indicators we investigated can point to certain trends. Rabbits treated with FCA showed more signs of acute and chronic inflammation, resulting in larger primary lesions, than rabbits treated with AVM or AVS. Secondary.lesions resulting from FIA booster injections were not larger than secondary lesions resulting from AdjuVac. The two AdjuVac formulations also showed evidence of inciting inflammation, in the form of injection site granulomas. Lesions resulting from the initial vaccination and from the booster vaccination were smaller in the AVS group than in the AVM group.

This research reconfirms that water-in-oil-based adjuvants with mycobacterial fractions can initiate high antibody production, while inducing physiological changes consistent with acute and chronic inflammation. The amount and type of mycobacteria used may affect the severity of inflammation. The type of oil we used in the AdjuVac emulsion (non-biodegradable mineral oil or squalene) did not seem to affect indicators of inflammation or antibody production during this 12 -week study, but a study with more robust sample sizes is needed to confirm or refute this hypothesis. AdjuVac effectively induces humoral immunity as well as moderate localized inflammation when paired with the GnRH-KLH antigen.

\section{ACKNOWLEDGMENTS}

We thank K. Crane for completing the ELISA assays and K. Bird, $H$. Martinez, and $K$. Temple for excellent animal care and handling assistance. This study was supported by the National Wildlife Research Center, USDA/APHIS

\section{COMPETING INTERESTS STATEMENT}

The authors declare no competing financial interests.

Received 26 January; accepted 3 July 2007

Published online at http://www.labanimal.com

1. Sanchez, Y. et al. Humoral and cellular immunity to hepatitis $B$ virus-derived antigens: comparative activity of Freund's complete adjuvant, alum and liposomes. Infect. Immun. 30 , 728-733 (1980).

2. Leenaars, P.P.A.M., Hendriksen, C.F.M., Angulo, A.F., Koedam, M.A. \& Claassen, E. Evaluation of several adjuvants as alternatives to the use of Freund's adjuvant in rabbits. Vet. 
Immunol. Immunopathol. 40, 225-241 (1994).

3. Steiner, J.W., Langer, B. \& Schatz, D.L. The local and systemic effects of Freund's adjuvant and its fractions. Arch. Pathol. 70, 424-434 (1960).

4. Broderson, J.R. A retrospective review of lesions associated with the use of Freund's adjuvant. Lab. Anim. Sci. 39, 400405 (1989).

5. Mallon, F.M., Graichen, M.E., Conway, B.R., Landi, M.S. \& Hughes, H.C. Comparison of antibody response by use of synthetic adjuvant system and Freund complete adjuvant in rabbits. Am. J. Vet. Res. 52, 1503-1506 (1991).

6. Gupta, R.K. et al. Adjuvants - a balance between toxicity and adjuvanticity. Vaccine. 11, 293-301 (1993).

7. Leenaars, M. \& Hendriksen, C.F.M. Critical steps in the production of polyclonal and monoclonal antibodies: Evaluation and recommendations. ILAR J. 46 269-279 (2005).

8. Stills, H.F. J. Adjuvants and antibody production: Dispelling the myths associated with Freund's complete and other adjuvants. ILAR J. 46 280-293 (2005).

9. Cooper, P.D. in Strategies in Vaccine Design (ed. Ada G.L.) 126-147 (R.G. Landes Company, Austin, 1994).

10. Niemi, S.M., Fox, J.G., Brown, L.R. \& Langer, R. Evaluation of ethylene-vinyl acetate copolymer as a non-inflammatory alternative to Freund's compete adjuvant in rabbits. $L a b$. Anim. Sci. 35, 609-612 (1985).

11. Johnston, B.A., Eisen, H. \& Fry, D. An evaluation of several adjuvant emulsion regimens for the production of polyclonal antisera in rabbits. Lab. Anim. Sci. 41, 15-21 (1991).

12. Bennett, B., Check, I.J., Olsen, M.R. \& Hunter, R.L. A comparison of commercially available adjuvants for use in research. J. Immunol. Meth. 153, 31-40 (1992).

13. Deeb, B.J., DiGiacomo, R.F., Kunz, L.L. \& Stewart, J.L. Comparison of Freund's and Ribi adjuvants for inducing antibodies to the synthetic antigen (TG)-AL in rabbits. $J$. Immunol. Meth. 152, 105-113 (1992).

14. Lipman, N.S., Trudel, L.J., Murphy, C.J. \& Sahali, Y. Comparison of immune response potentiation and in vivo inflammatory effects of Freund's and RIBI adjuvants in mice. Lab. Anim. Sci. 42, 193-197 (1992).

15. Smith, D.E., O'Brien, M.E., Palmer, V.J. \& Sadowski, J.A. The selection of an adjuvant emulsion for polyclonal antibody production using a low-molecular-weight antigen in rabbits. Lab. Anim. Sci. 42, 599-601 (1992).

16. Leenaars, P.P.A.M., Hendriksen, C.F.M., Koedam, M.A.,
Claassen, I. \& Claassen, E. Comparison of adjuvants for immune potentiating properties and side effects in mice. Vet. Immunol. Immunopathol. 48, 123-138 (1995).

17. Leenaars, M., Koedam, M.A., Hendriksen, C.F.M. \& Claassen, E. Immune responses and side effects of five different oilbased adjuvants in mice. Vet. Immunol. Immunopathol. 61 , 291-304 (1998).

18. Leenaars, P.P.A.M. et al. Assessment of side effects induced by injection of different adjuvant/antigen combinations in rabbits and mice. Lab. Anim. 32, 387-406 (1998).

19. Claassen, E., de Leeuw, W., de Greeve, P., Hendriksen, C. \& Boersma, W. Freund's complete adjuvant: an effective but disagreeable formula. $44^{\text {th }}$ Forum in Immunology Res. Immunol. 143, 478-483 (1992).

20. Levy, J.K., Miller, L.A., Crawford, P.C., Ritchey, J.W., Ross, M.K. \& Fagerstone, K.A. GnRH immunocontraception of male cats. Theriogenology 62, 1116-1130 (2004).

21. Killian, G., Miller, L., Diehl, N.K., Rhyan, J. \& Thain, D. Evaluation of three contraceptive approaches for population control of wild horses. Proc. Veretebr. Pest Conf. 21, 263-268 (2004).

22. Killian, G., Miller, L., Rhyan, J. \& Doten, H. Immunocontraception of Florida feral swine with a singledose GnRH vaccine. Am. J. Reprod. Immunol. 55(5), 378384 (2006).

23. Miller, L.A., Rhyan, J.C. \& Drew, M. Contraception of bison by $G n R H$ vaccine: a possible means of decreasing transmission of brucellosis in bison. J. Wildl. Dis. 40(4), 725-730 (2004).

24. Miller, L.A., Johns, B.E. \& Killian, G.J. Immunocontraception of white-tailed deer with GnRH vaccine. Am. J. Reprod. Immunol. 44(5), 266-274 (2000).

25. Favarato, M. \& Zatta, P. Chemico-clinical characterization of rabbit serum. J. Appl. Rabbit Res. 13, 14-15 (1990).

26. Harkness, J.E. \& Wagner, J.E. in The Biology and Medicine of Rabbits and Rodents 4th edn. 85-88 (Willians and Wilkens, Media, PA, 1995).

27. Duncan, J.R., Prasse, K.W. \& Mahaffey, E.A. in Veterinary Laboratory Medicine Clinical Pathology 3rd ed. 184-187 (Iowa State University Press, Ames, IA, 1994).

28. Byars, N.E. \& Allison, A.C. Adjuvant formulation for use in vaccines to elicit both cell-mediated and humoral immunity. Vaccine. 5, 223-228 (1987).

29. Johnston, J.K. \& Morris, D.D. in Large Animal Internal Medicine 2nd edn. (ed. Smith, B.P.) 489-497 (Mosby-Year Book, Inc., St. Lois, MO, 1996). 